\title{
A New Manufacturing Route to Picoxystrobin
}

Yu Chen, ${ }^{1), 2)}$ Huan Lu, ${ }^{2}{ }^{2}$ Hui Dai, ${ }^{2)}$ Wansheng Yu, ${ }^{2)}$ Xianhua Pan ${ }^{1,2)}$ *

1) School of Perfume and Aroma Technology, Shanghai Institute of

Technology, 100 Haiquan Rd., Shanghai, 201418, P.R. China.

2) Shanghai Research Institute of Fragrance and Flavor Industry, 480

Nanning Rd., Shanghai, 200232, P.R. China.

\section{Supporting Information}

\section{Table of Contents}




\section{General Experimental}

${ }^{1} \mathrm{H}(400 \mathrm{MHz})$ and ${ }^{13} \mathrm{C}(100 \mathrm{MHz})$ NMR spectra were recorded on a Bruker Avance 400 spectrometer in $\mathrm{CDCl}_{3}$ using tetramethylsilane (TMS) as internal standards. 
2. Appendix - Copies of ${ }^{1} \mathrm{H}$ and ${ }^{13} \mathrm{C}$ NMR data

S-3 


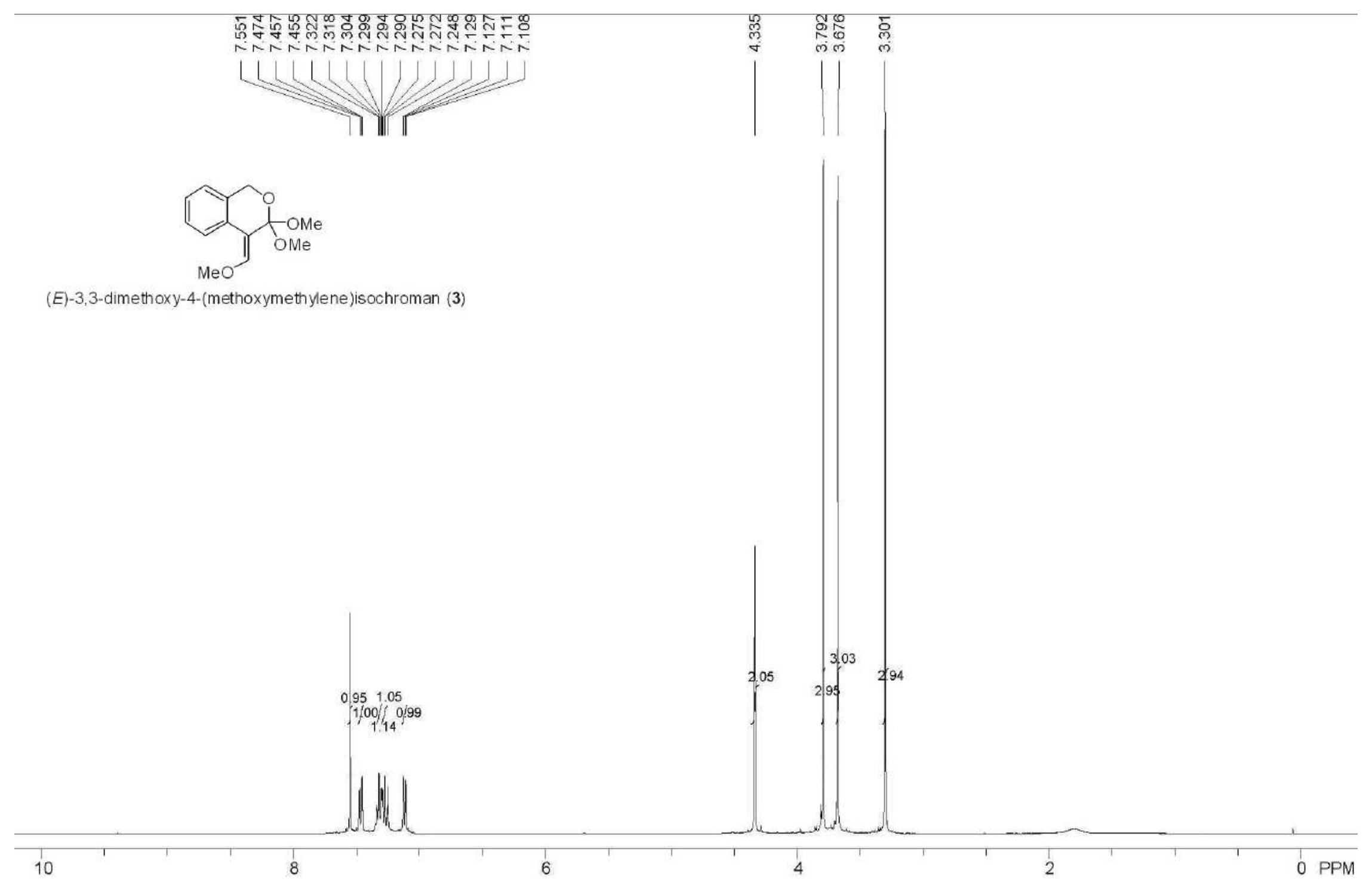



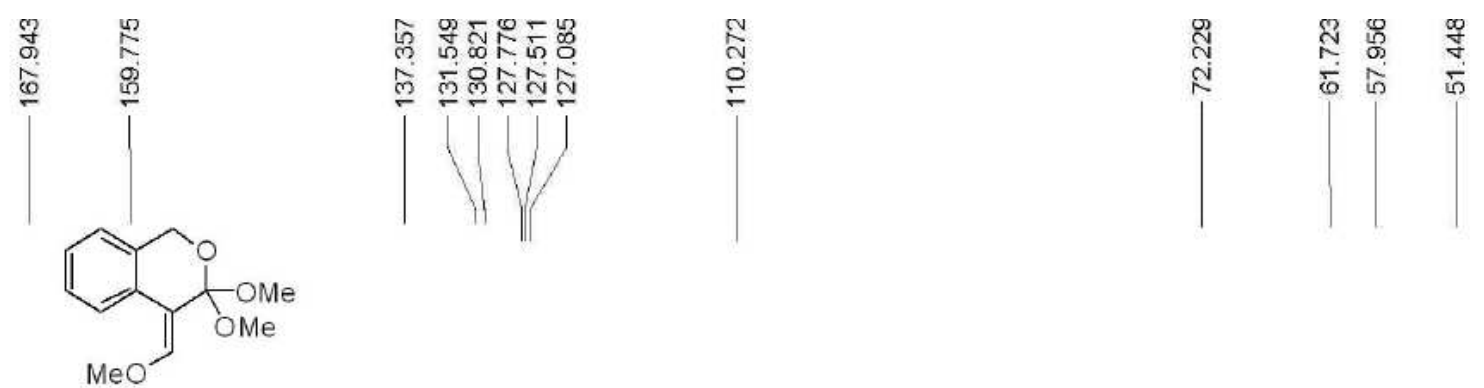

(E)-3,3-dimethoxy-4-(methoxymethylene)isochroman (3)

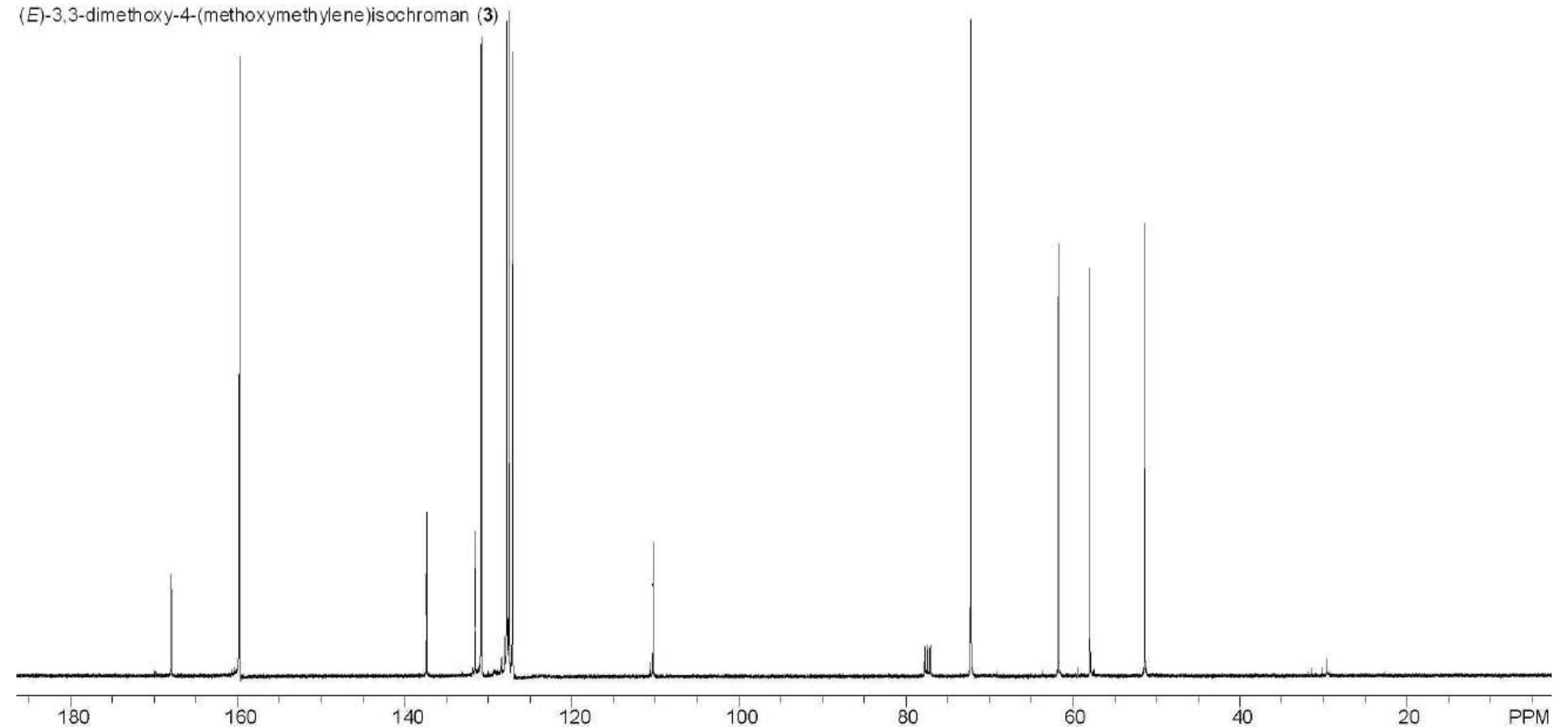




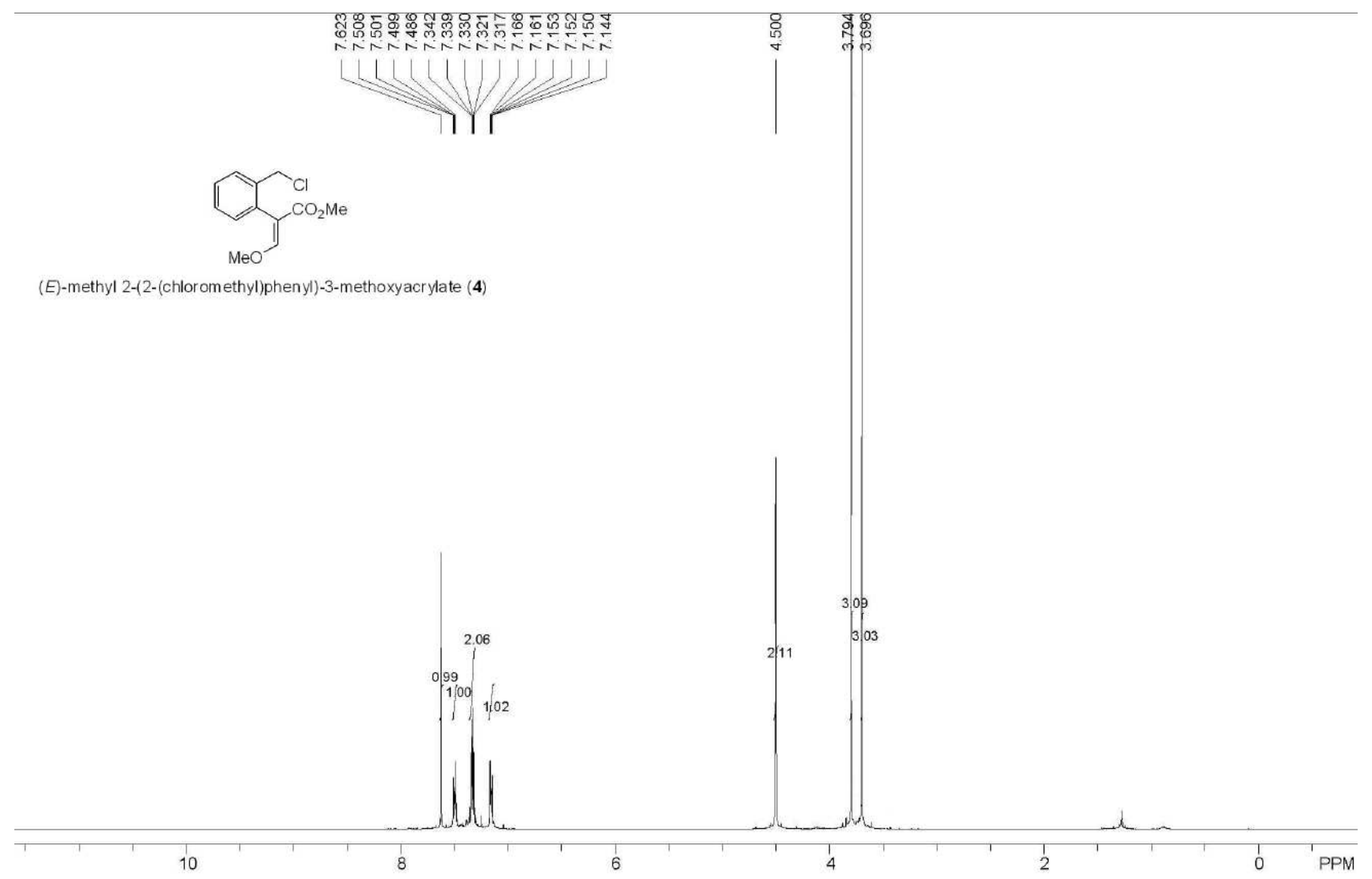




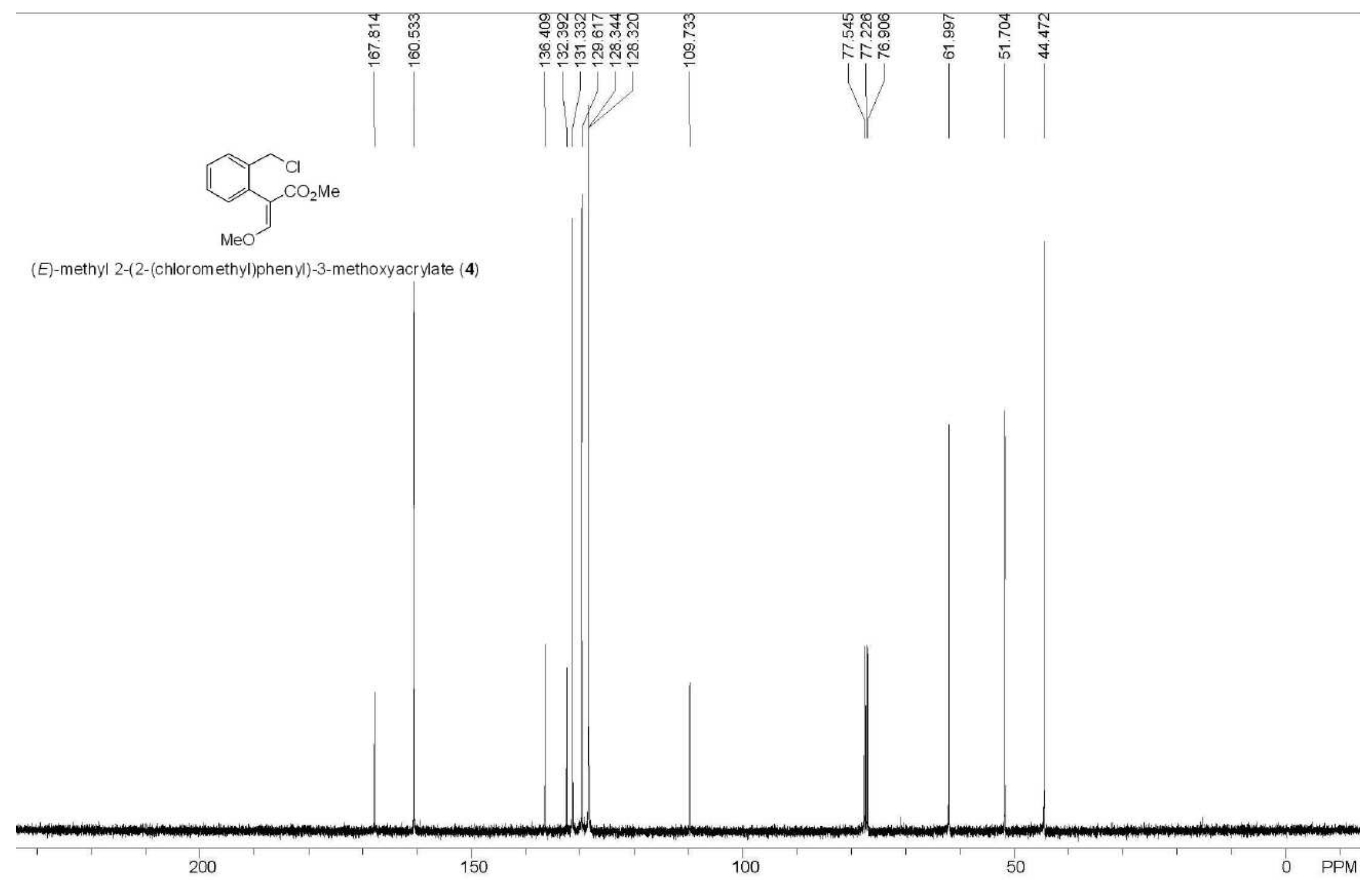




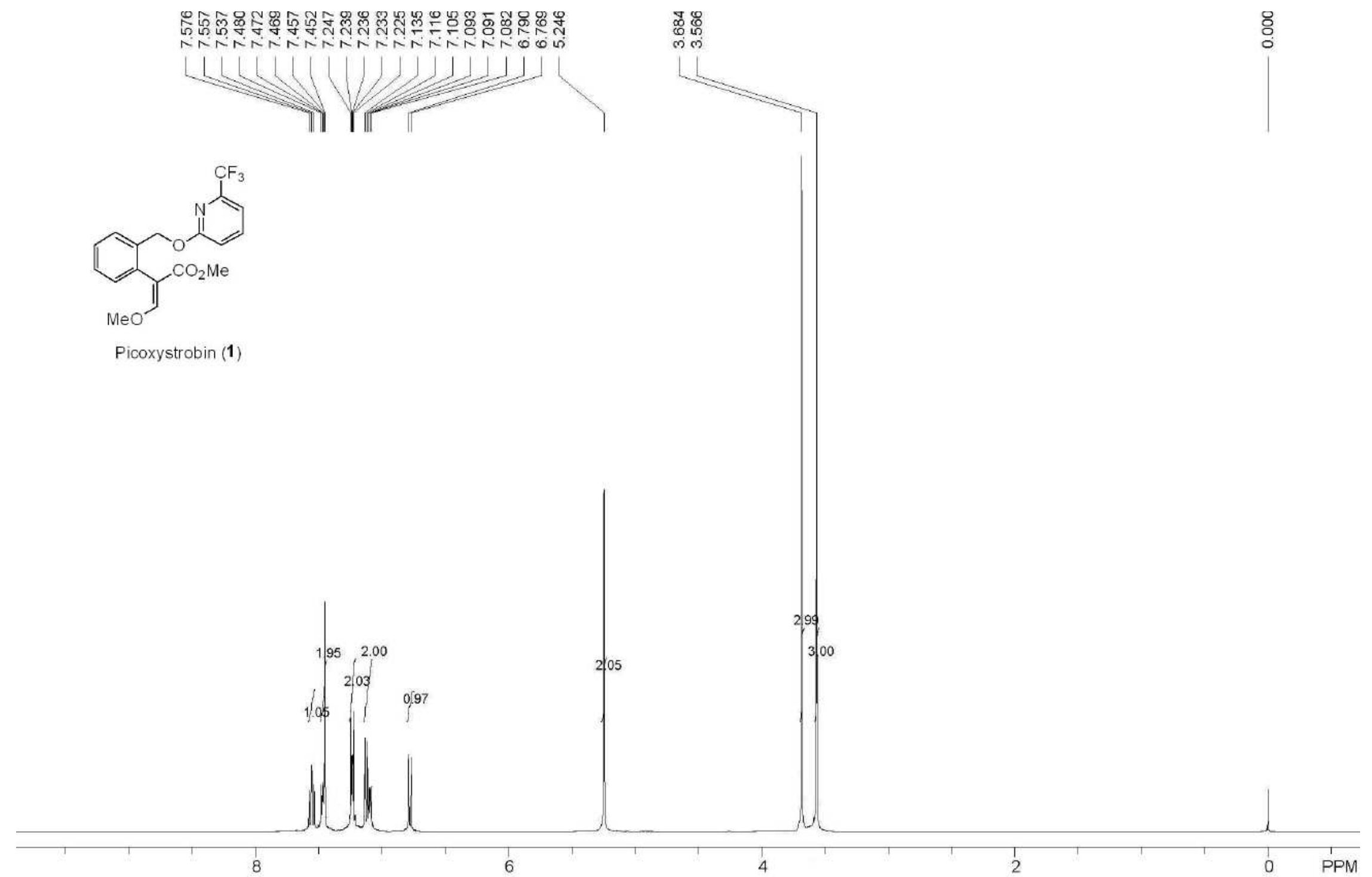




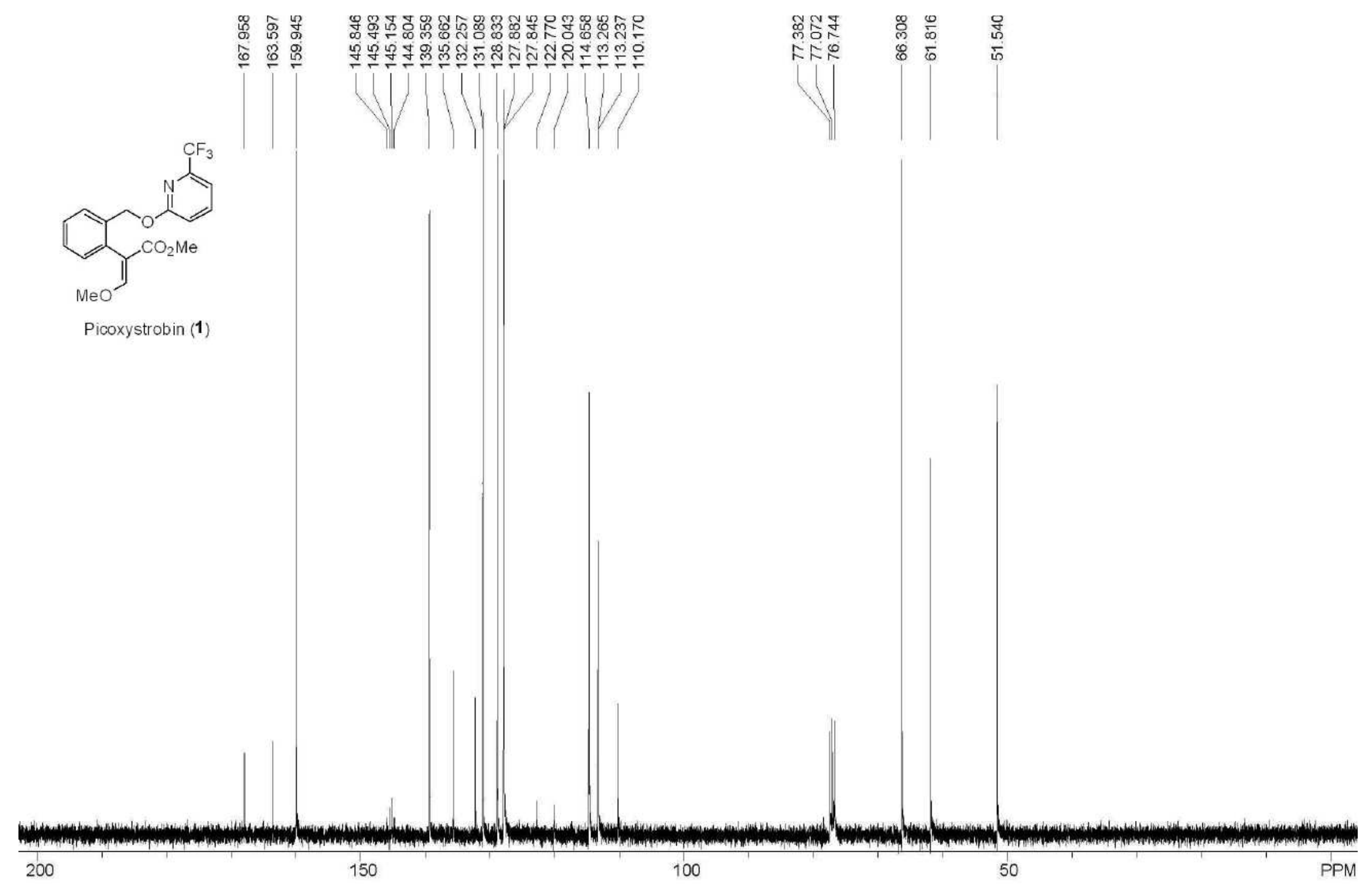




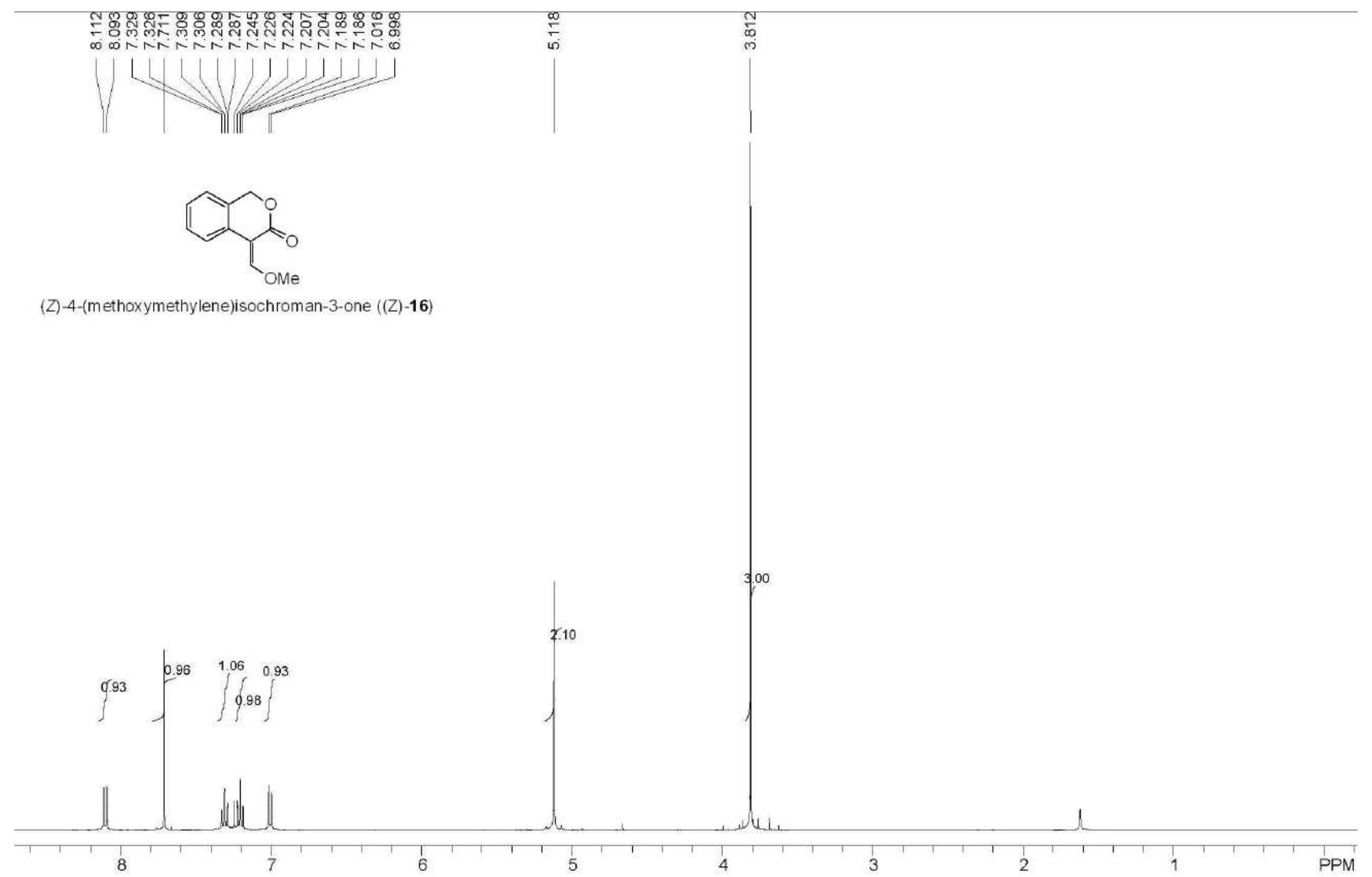




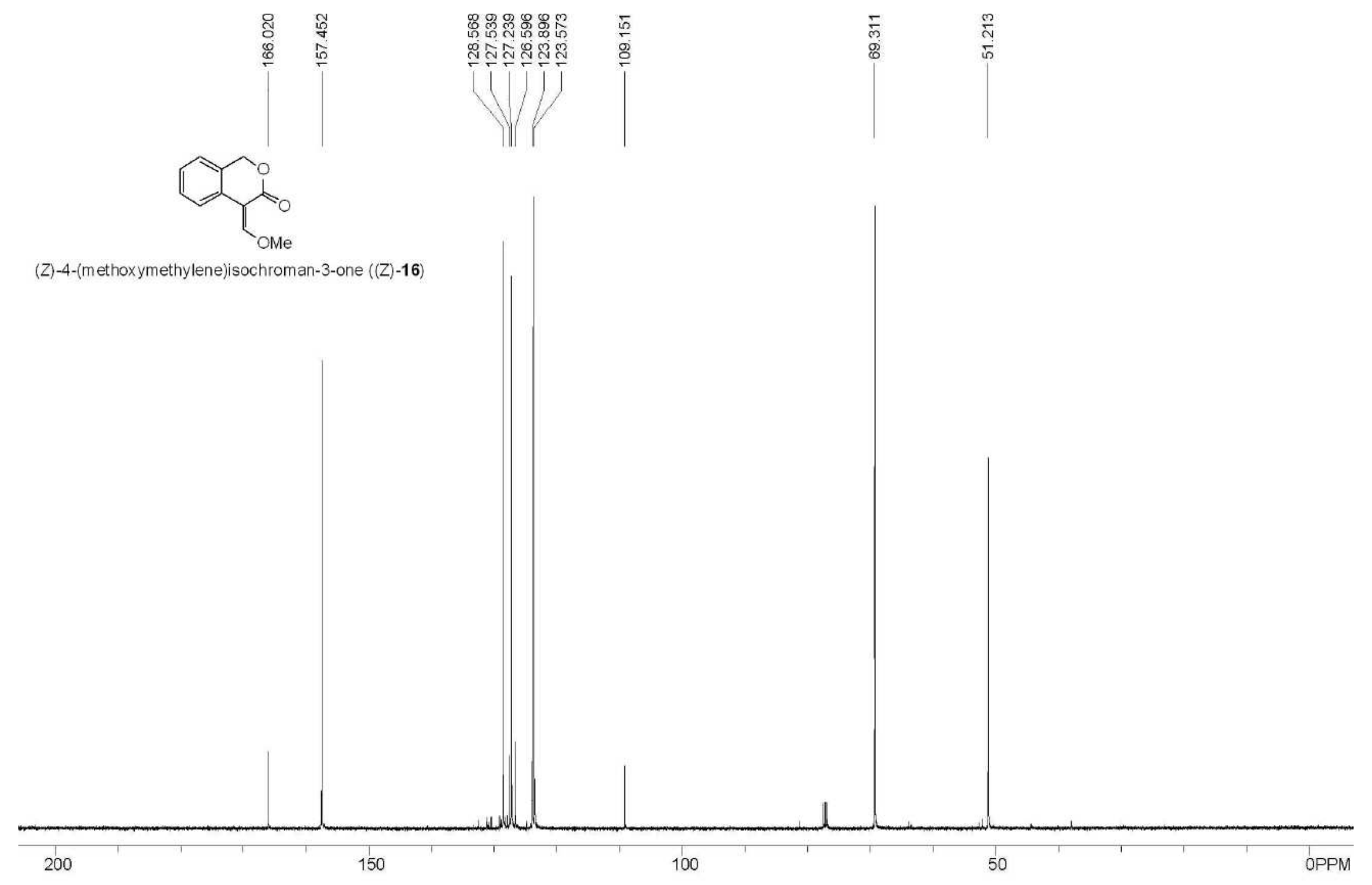




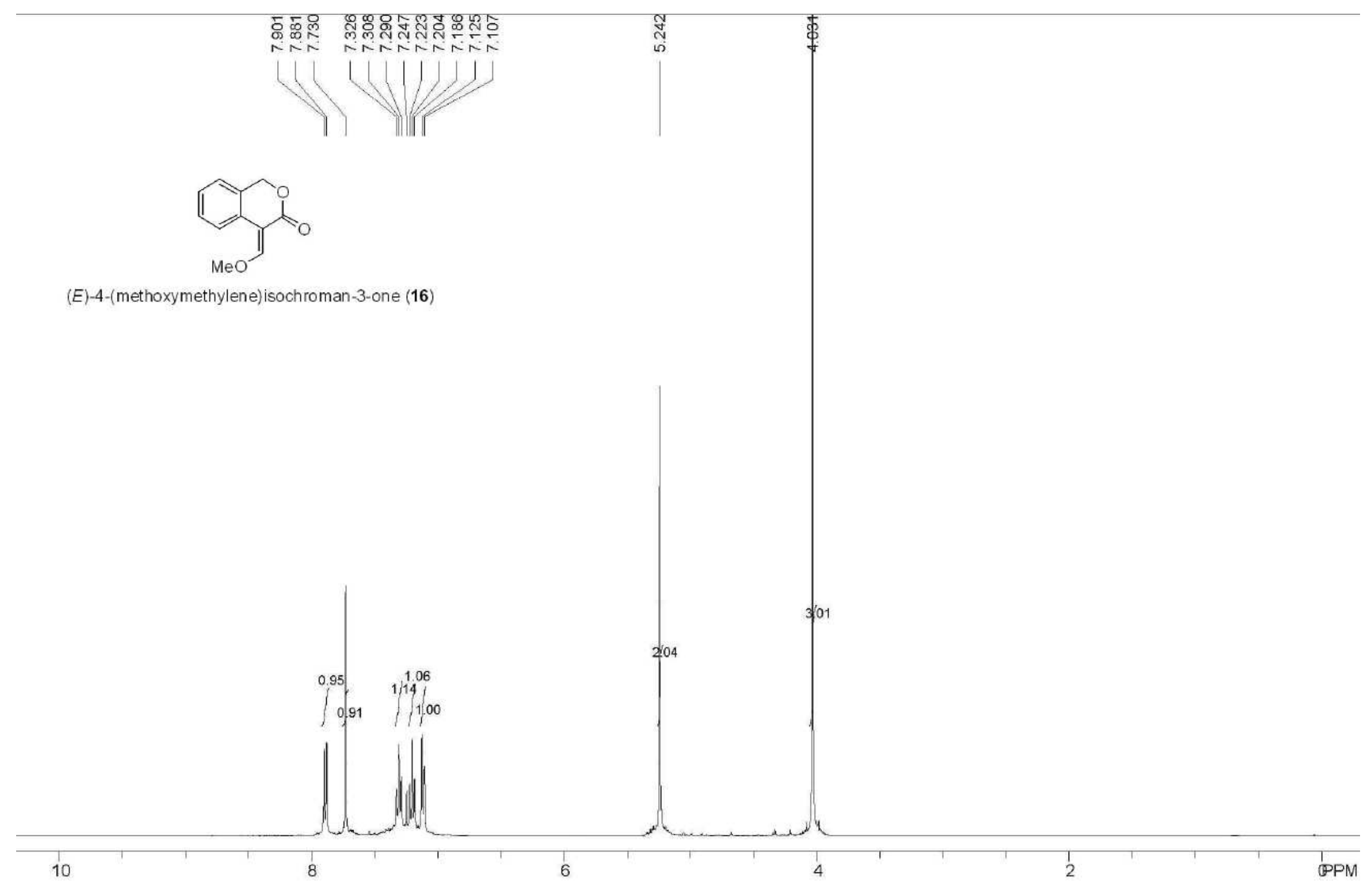




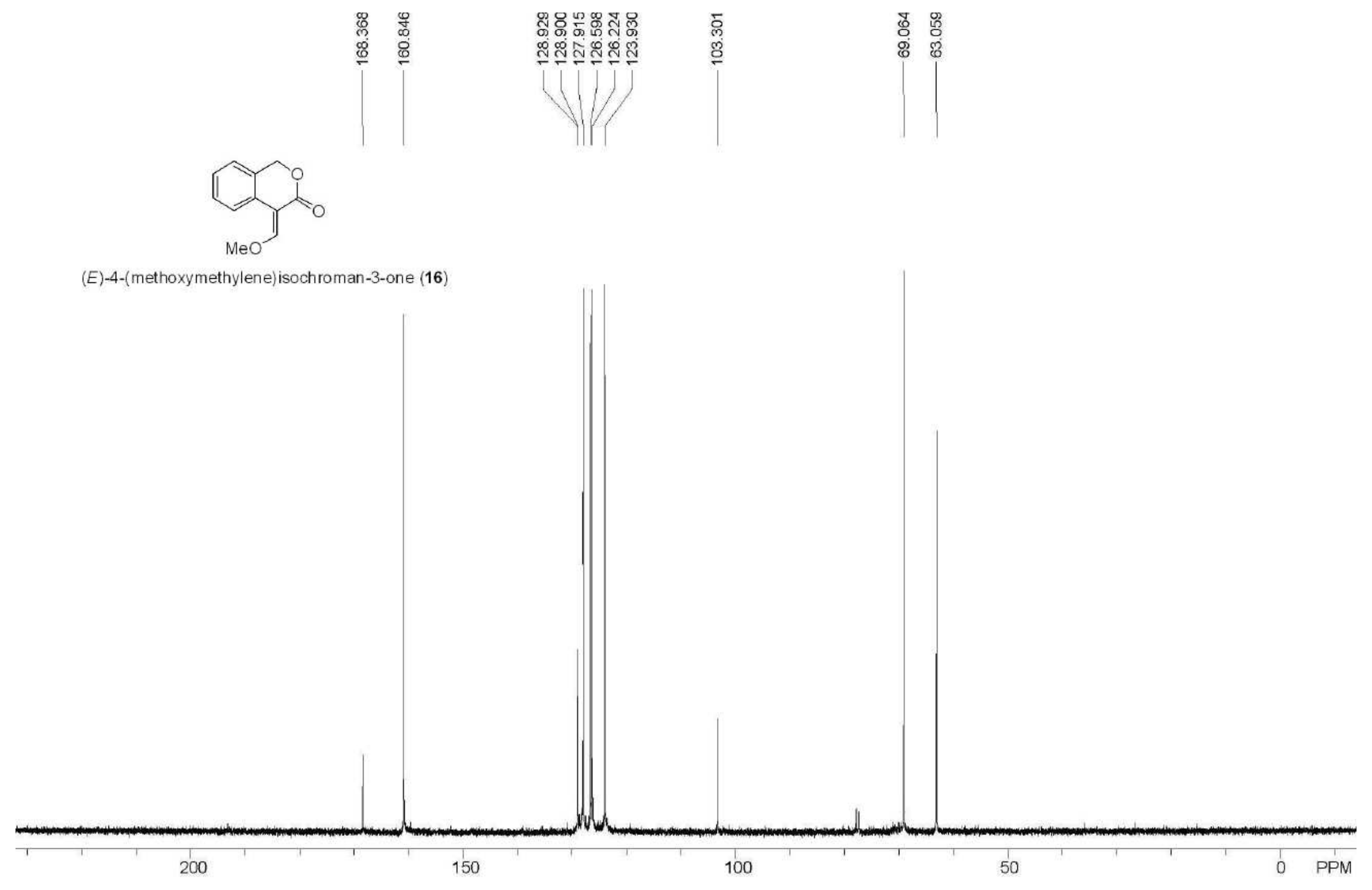




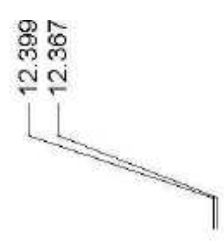

(E)-4-(hydroxymethylene)isochroman-3-one (15)

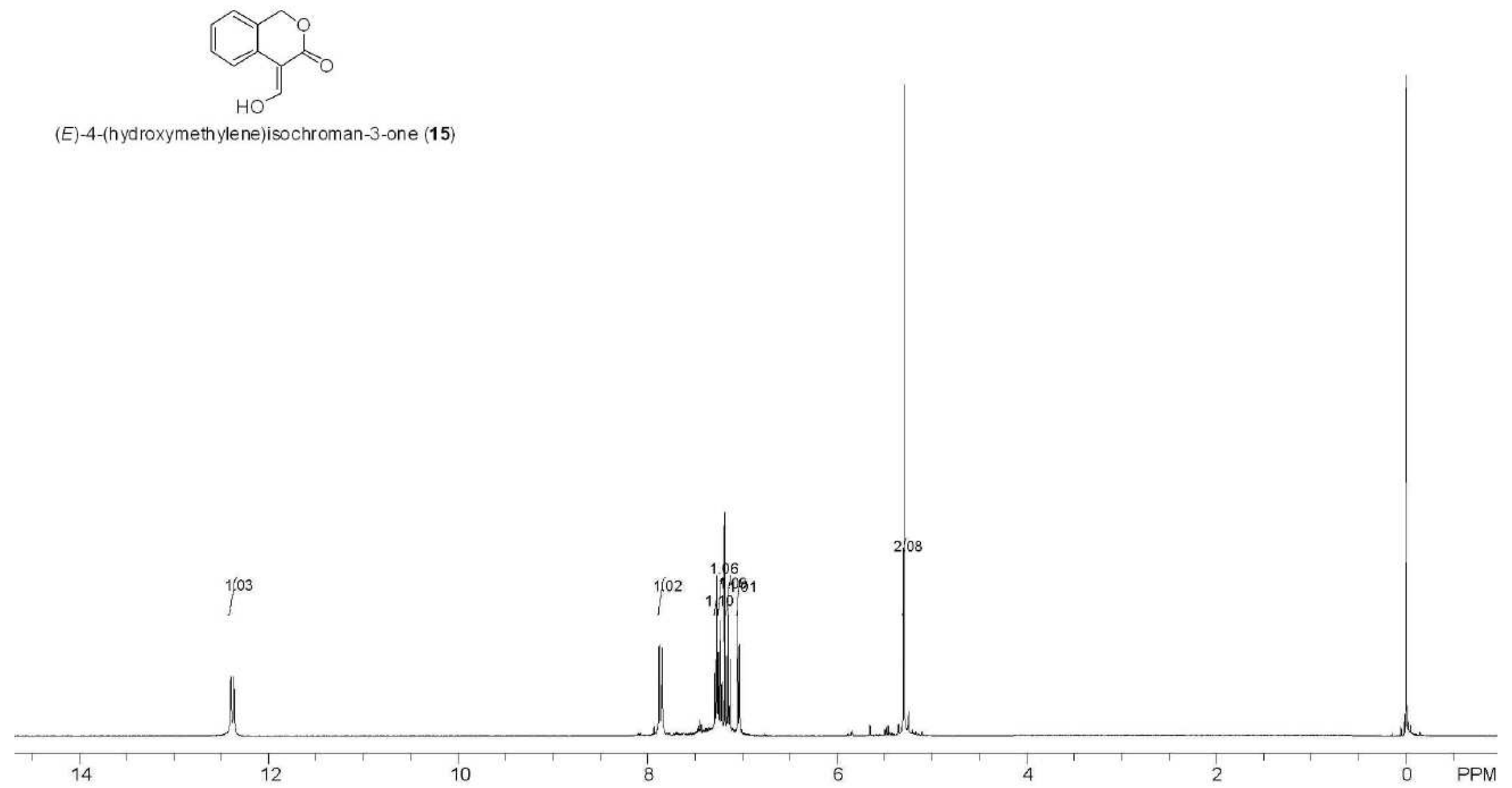

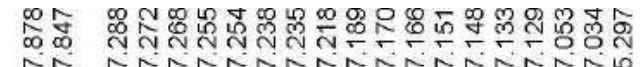

L

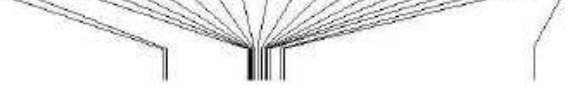

